\title{
A AUSÊNCIA DO PODER PÚBLICO NO DESCARTE DOMÉSTICO DE MEDICAMENTOS
}

THE ABSENCE OF PUBLIC POWER IN THE DOMESTIC DISPOSAL OF MEDICINES

\author{
OLIVEIRA, Bianca Aparecida Domingos ${ }^{1}$; TAKETANI, Natália Franco²; \\ ${ }^{1}$ Graduando do Curso de FARMÁCIA - Universidade São Francisco); \\ ${ }^{2}$ Professor do Curso- Universidade São Francisco) \\ bianca.domingos@mail.usf.edu.br
}

\begin{abstract}
RESUMO. Neste trabalho é apresentada a problemática do descarte doméstico de medicamento, relacionando com a ineficiência da aplicabilidade das normas que o regulam. $\mathrm{O}$ presente trabalho foi baseado em revisão bibliográfica que busca contextualizar a problemática aqui enfrentada. Expõe as principais razões que levam ao descarte residencial incorreto de medicamentos e por consequência ao uso irracional, expandindo os danos ambientais, sendo eles, a propaganda de medicamentos que estimula a aquisição desnecessária, não adesão ao tratamento prescrito, criação de farmácias caseiras, colocando em risco a saúde dos seres vivos. Além de elencar os principais instrumentos normativos e regulamentadores, sendo eles, ANVISA (Agência Nacional de Vigilância Sanitária e CONAMA (Conselho Nacional do Meio Ambiente), onde seu objetivo é a gestão do PGRSS (Plano de Gerenciamento de Resíduos de Serviços de Saúde) para os estabelecimentos de saúde, onde seu objetivo é a minimização de resíduos provenientes de medicamentos residências e proporcionar a estes resíduos um encaminhamento seguro de forma apropriado, zelando pela proteção dos trabalhadores envolvidos, preservação da saúde pública e do meio ambiente. Evidenciando com base nos resultados revisados segundo a literatura a relevância da detecção de genes de resistência a partir de bactérias presentes na natureza, que podem ser em parte provenientes da dos mecanismos de resistência despejados no ambiente. Para ao fim, concluir pela ausência do Poder Público em efetivar tanto os instrumentos normativos, como propor políticas públicas que enfrente as consequências do descarte incorreto de medicamentos residenciais.
\end{abstract}

Palavras-chave: Descarte Residencial de Medicamentos; Logística Reversa; Meio Ambiente e a Resistência Microbiana

ABSTRACT. This paper presents the problem of domestic drug disposal, related to the inefficiency of the applicability of the regulations that regulate it. The present work was based on a bibliographical review that seeks to contextualize the problematic here faced. It exposes the main reasons that lead to the incorrect residential disposition of medicines and consequently to the irrational use, expanding the environmental damages, being: the advertisement of medicines that stimulates the unnecessary acquisition, non-adherence to the prescribed treatment, creation of home pharmacies, putting in the health of living beings. In addition to listing the main normative and regulatory instruments, being ANVISA (National Sanitary Surveillance Agency and CONAMA (National Environmental Council), where its objective is the management of the PGRSS (Health Services Waste Management Plan) for the health centers, where their objective is the minimization of residues from medicines residences and to provide to these residues a safe route of appropriate form, taking care of the protection of the workers involved, preservation of public health and of the environment. Evidence of the 
relevance of the detection of resistance genes from naturally occurring bacteria, based on the results reviewed, may be due in part to resistance mechanisms released into the environment. Finally, we conclude by the absence of the Public Power to implement both the normative instruments and propose public policies that face the consequences of the incorrect disposal of residential medicines.

Keywords: Residential Disposal of Medications; Reverse logistic; Environment and Microbial Resistance

\section{INTRODUÇÃO}

Nas últimas décadas, houve um imensurável aumento no consumo de medicamentos, tanto, por conta dos avanços da ciência quanto da expansão de grandes indústrias farmacêuticas, juntamente com a larga promoção comercial (RODRIGUES, 2009). Até o começo do século XIX o uso de medicação era voltado apenas para medicações de fórmula natural, ou seja, de estrutura química e natureza desconhecidas, o que aponta o quanto os medicamentos ainda precisavam passar por avanços (STORPIRTS et al., 2006). Atualmente, no país, criou-se uma cultura de que farmácias não passam de um mero comércio e que os medicamentos são vistos como mercadorias, assim como qualquer outro produto e isto acaba estimulado fortemente o consumo de medicamentos de forma indiscriminada, em vista de que somente a prescrição médica não tem poder de conseguir atuar como prevenção quanto á automedicação (BALISA 2010). Porém, mesmo com toda tecnologia acessível, permanece a omissão de informação quanto ao método apropriado de descarte de medicamentos não empregados por extensa parcela da população. Esta situação se aplica por conta do fascínio por novidades terapêuticas, uma gigantesca oferta em quantidade e variedade de produtos farmacêuticos, das quais muitas são apenas variações de fórmulas já conhecidas e devido marketing grosseiro aplicado a produtos de saúde, destaca Castro (2000).

Atualmente este cenário descrito não declinou com o passar do tempo, mas tomou proporções gigantescas, em que a população está acostumada a criar suas próprias "farmacinhas" em casa, por conta da cultura brasileira de automedicação e a fácil aquisição acabaram por gerar nas residências brasileiras um acúmulo de medicamentos, tendo como resultado um risco considerável para a saúde e para o meio ambiente, tendo em vista a contribuição para o descarte de medicamentos de forma errônea (FIRMO, 2012).

Os fármacos são compostos químicos biologicamente ativos criados e desenvolvidos para obterem mecanismos de ação específicos que são jogados na natureza à medida que os medicamentos são utilizados ou quando desprezados, podendo estar na sua forma inalterada, nos metabólitos ou produtos de transformação (DAUGHTON, 2003). O lixo comum é constituído por ser a principal fonte, com destino ao meio ambiente para tal contaminação, devido o momento em que chega ao seu destino final.

No caso de aterro sanitário que não conta com estruturas adequadas para destino final, com material que consegue evitar que os poluentes passem para o solo (manta impermeabilizadora), os fármacos por consequência podem chegar até o lençol freático em concentrações altas, podendo ser até maiores do que por meio do esgoto (AWAD, 2010).

$\mathrm{Na}$ lista dos medicamentos mais descartados estão os antimicrobianos, uma classe de medicamentos que á pouco tempo passou a ser dispensado sob retenção de receita, sendo a terceira classe de fármacos mais descartada, a liberação do mesmo no meio ambiente acaba em 
sua maioria resultado de seleção e indução de resistência bacteriana, por ser liberado no meio ambiente, esse tipo de descarte é muito preocupante (ROCHA, 2009).

Há estudos que comprovam que os medicamentos são fatores preeminentes que mais acarretam intoxicações no Brasil, ocupando a posição de primeiro lugar nos estudos estatísticos do SINITOX (Sistema Nacional de Informações Tóxico Farmacológicas) (BORTOLETTO; BOCHNER, 1999; MARGONATO et al., 2008).

Os programas de coleta de medicamentos têm a capacidade de diminuir o volume de medicamentos que de alguma forma permeia o meio ambiente como grandes poluentes e facilitam o uso racional de medicamentos (BUENO, 2009). Por fim a logística reversa, citada por Awad (2010) constitui-se no curso inverso de materiais, empregando os mesmos processos de um planejamento logístico convencional, que normalmente é caracterizado por armazenagem, coleta, transporte, destinação final, entretanto, essas ações ocorrem de maneira inversa, onde, o ponto de partida é pelas mãos dos clientes. Esse sistema da logística reversa é baseado no princípio da ampliação da responsabilidade do produtor da poluição pela qual o medicamento foi fabricado, pelo efeito do pós-consumo dos seus produtos (BRASIL, 2010c). Cabe ao fabricante se responsabilizar pela coleta e destinação adequada dos resíduos dos seus produtos do pós-consumo que possui ameaça ao meio ambiente (VETTORAZZI; VENAZZI 2008).

\section{METODOLOGIA}

Este artigo teve como embasamento pesquisas de referências bibliográficas. Pressupôs o levantamento de textos publicados em revistas científicas, que constituiu a principal fonte de pesquisa. Outras fontes utilizadas foram livros, dissertações de mestrado e trabalhos científicos. Foram pesquisadas as bases de dados dos Periódicos: revistas cientificas de saúde, PubMed, Science Direct, Scielo, Lilacs e Google Acadêmico com páginas em Português, Inglês e Espanhol.

Neste sentido, as palavras-chaves usadas nesta pesquisa foram: métodos de análise e quantificação de fármacos; análise dos aspectos legais e ambientais do descarte de resíduos de medicamentos; aspectos toxicológicos do descarte de medicamentos; caracterização dos medicamentos descartados, consciência ambiental; gerenciamento de resíduos de medicamentos; tratamento de resíduos medicamentos e logística reversa de medicamentos e aspectos legislativos do descarte de medicamentos residências.

\section{RESULTADOS E DISCUSSÃO}

\section{Histórico da evolução dos medicamentos}

Os medicamentos conhecidos como grandes inovações tecnológicas, ofertam tanto benefícios quanto riscos a população e o discernimento da existência desses riscos pelo público é essencial (MENDES, 2008).

Nas últimas décadas, houve um imensurável aumento no consumo de medicamentos, tanto, por conta dos avanços da ciência quanto da ampliação de grandes indústrias farmacêuticas, juntamente com a larga promoção comercial. Isso dado que, a inserção consistente de novos fármacos, acabou levando para população perspectivas terapêuticas na cura de enfermidades até aquele momento letais, acima de tudo na extensão de doenças infecciosas (RODRIGUES, 2009). Até o começo do século XIX o uso de medicação era voltado 
apenas para medicações de fórmula natural, ou seja, de estrutura química e natureza desconhecidas, o que aponta o quanto os medicamentos ainda precisavam passar por avanços (STORPIRTS, 2006). No século XX, com a crescente tecnologia e consequentemente o aumento da eficiência no atendimento médico e prevenção de doenças, a expectativa de vida da década de 1990 ultrapassou os sessenta e cinco anos, em relação a década de 1940 que era menor que quarenta anos (WHO,1997).

Já no século XXI, torna-se indispensável à utilização de medicamentos para a cura de doença, manutenção do tratamento e para o controle dos sintomas. (BILA; et al., 2003; BUENO; et al., 2009).

\section{Consumo de medicamentos no Brasil}

Segundo levantamento, a Organização Mundial de Saúde (OMS) estabelece uma estimativa que a maior parcela de todos os medicamentos é prescrita e/ou dispensado de modo equivocado (QUELUZ; LEITE, 2008). Levando em consideração o fato de mais da metade dos pacientes não utilizarem esses medicamentos corretamente, a OMS propôs o conceito de Uso Racional de Medicamentos (URM), onde, compreende-se que essa definição consiste no instante em que o paciente recebe medicamentos adequados para suas condições e características clínicas, atendendo ás necessidades individualmente com dose, período de tratamento e custo adequado (OMS, 1985).

No entanto, a população brasileira com o passar do tempo e com a facilidade de adquirir medicamentos, desenvolveu o hábito de se automedicar. O Brasil se encontra entre os dez países que mais consomem medicamentos no mundo, segundo dados do Conselho Federal de Farmácia (CFF). Atualmente, no país, criou-se uma cultura de que farmácias não passam de um mero comércio e que os medicamentos são vistos como mercadorias, assim como qualquer outro produto e isto acaba estimulado fortemente o consumo de medicamentos de forma indiscriminada, em vista de que somente a prescrição médica não tem poder de conseguir atuar como prevenção quanto á automedicação (BALISA, 2010). Esta situação se aplica por conta do fascínio por novidades terapêuticas, uma gigantesca oferta em quantidade e variedade de produtos farmacêuticos, das quais muitas são apenas variações de fórmulas já conhecidas e devido marketing grosseiro aplicado a produtos de saúde, destaca Castro (2000).

\section{Dimensionando o problema}

Atualmente, mesmo com toda tecnologia acessível, permanece a omissão de informação quanto ao método apropriado de descarte de medicamentos não empregados por extensa parcela da população. $\mathrm{O}$ descarte de medicamentos vencidos no lixo residencial comum se encaminha a implicações à saúde pública fundamentando realidade nacional onde há pessoas que dependem de restos adquiridos nos "lixões" da cidade para sobreviverem, sujeitando-se a exposição aos riscos característicos aos variados produtos (VETTORAZZI; VENAZZI 2008).

Os estudos realizados por a Rocha (2009) apontam que medicamentos estocados em residências são um dos principais motivos para o descarte inadequado, pois é a principal origem dos resíduos descartados. Há fatores que contribuem fortemente para esse estoque desnecessário, são descritos por Schenkel (2004) como interrupções no tratamento, amostras grátis, automedicação, farmácia caseira e medicamentos em desuso por conta de reações adversas. 
Segundo a Agência Nacional de Vigilância Sanitária (ANVISA), estima-se que a cada ano no Brasil, aproximadamente 30 mil toneladas de remédios são jogados fora (CARNEIRO, 2011). E a incumbência da vigilância sanitária infelizmente ainda se encontra limitada a serem cumpridas apena as leis e regulamentações a órgãos de serviço de atendimento a saúde como: hospitais, drogarias, farmácias, indústrias, entretanto para o consumidor (população) ainda não foram instituídas normas de descarte doméstico de medicamentos (AKATU, 2008).

Quando há descarte de medicamentos de forma inadequada há riscos de promoção de graves impactos no meio ambiente e consequentemente na saúde pública.

A atenção voltada ao impacto ambiental por conta dos fármacos é de suma importância, pois os mesmos desempenhem um papel essencial para tratamentos e profilaxias de numerosas patologias, que podem acabar induzindo efeitos adversos e catastróficos atingindo diretamente organismos vivos não alvos (BOXALL, 2004; CELIZ et al., 2009; CHRISTEN et al., 2010; KIM; AGA, 2007; ZIYLAN; INCE, 2011).

É preocupante não apenas o aumento do consumo de medicamentos, mas também o destino final destes produtos, pois devem se considerados todas as formas de eliminação no meio ambiente, direta ou indiretamente, visto que, tais substâncias químicas contaminam o solo e as águas, podendo causar danos à saúde humana, aos seres vivos e ao ecossistema presente. Destaca-se que a poluição ambiental causada por medicamentos é silenciosa (COSTA; COSTA, 2011).

No Brasil, existe uma quantidade insuficiente de pesquisadores que estudam a extensão de contaminação ambiental por fármacos (PONEZI et al., 2008; KUMMERER, 2009). Segundo estudos não há publicações de dados da OMS precisos em relação à quantidade total de fármacos consumidos a nível mundial de fato. Devido o consumo e administração de formas incorretas dos agentes terapêuticos á uma variação considerável de região para região. No entanto há estudos que mostram os fármacos mais utilizados e que são encontrados no meio ambiente, os mesmos são pertencentes de diferentes classes terapêuticas, com ou sem prescrição médica, destes destacam os anti-inflamatórios, antibióticos, antiepiléticos, contrastantes, esteroides sintéticos, citostáticos, antidepressivos e ainda broncodilatadores (CALISTO, 2009; ZIYLAN et al., 2011).

\section{Motivos que influenciam na produção de resíduos medicamentosos residenciais}

Com base às consequências há algumas motivações que contribuem fortemente para a utilização irracional dos medicamentos e sua produção de resíduos excessivos como resultado. Segundo Mendes et al., (2010) de modo geral são numerosas as razões das sobras demasiada de medicamentos, dentre elas, podem ser citadas como bons exemplos:

- Apresentações de especialidades farmacêuticas em quantidades superiores das posologias usualmente aplicadas;

- Alteração do plano medicamentoso durante o tratamento;

- Mercadologia /propaganda de medicamentos que estimulem a aquisição desnecessária;

- Não adesão ao recurso terapêutico.

Atualmente este cenário descrito não declinou com o passar do tempo, mas tomou proporções gigantescas, em que a população está acostumada a criar suas próprias "farmacinhas" em casa, por conta da cultura brasileira de automedicação e a fácil aquisição acabaram por gerar nas residências brasileiras um acúmulo de medicamentos, tendo como resultado um risco considerável para a saúde e para o meio ambiente, tendo em vista a contribuição para o descarte de medicamentos de forma errônea (FIRMO et al., 2003). 
As célebres farmácias caseiras como são popularmente conhecidas, geralmente compostas por algumas fórmulas destinadas para utilização em casos de emergências, que são vendidos sem prescrição médica, como analgésicos, antitérmicos e antigripais, comumente conhecidos como MIP'S (Medicamentos Isentos de Prescrição). Consequentemente, torna-se comum conter também sobras de medicamentos que necessitam de receitas, tais como corticoides, antibióticos, entre outros, podendo ficar armazenados até a expiração da sua data de validade ou até para possível utilização posterior, sendo um fator de preocupação para a saúde pública (BUENO; WEBER; OLIVEIRA, 2009). Após o préstimo do medicamento por expirar o prazo de validade, devem ser interrompida a utilização e seguir para o descarte, a fim de evitar problemas, como a falta de efetividade, possíveis reações adversas, intoxicações, uso sem necessidade, uso sem indicação, poluição do meio ambiente, entre outros (RODRIGUES, 2009).

Entretanto é importante frisar que o consumidor representa uma notável parcela da população brasileira que não possui discernimento do descarte de resíduos medicamentosos, sobretudo das ameaças quanto ao acervo de medicamentos vencidos por uso insensato, o que os tornam incapazes de assumir conduta apropriada em relação aos medicamentos que já não tem mais serventia sendo por finalização de tratamento ou por conta da data de validade obsoleta (GIL, 2007). Segundo estudos realizados por Vettorazzi et al., (2008) por conta do discernimento da sua relativa destrutibilidade, a população (consumidores) deve ser referido como sendo o elo mais frágil da cadeia de produtividade e aquisição. De modo que por conta da globalização, resultaram no acesso a todos os medicamentos e às informações sobre eles, de forma rápida e facilitada. Por meio do exagerado consumismo e desenvolvimento do livre comércio (internet), houve mudanças e crescente evolução, que fizeram surgir novos parâmetros inerentes à segurança, como, por exemplo:

- Automedicação;

- Venda ilegal de medicamentos pela Internet;

- Fabricação e venda de medicamentos falsificados (falta de qualidade e segurança);

- Uso de medicamentos tradicionais por motivos inadequados (utilização do medicamento para se beneficiar de seus efeitos secundários, como perda de peso);

- Uso de plantas medicinais com outros medicamentos com potencial para interações medicamentosas adversas.

\section{Descarte de resíduos medicamentosos}

Os fármacos são compostos químicos biologicamente ativos criados e desenvolvidos para obterem mecanismos de ação específicos, que são despejados no ambiente a medida que os medicamentos são utilizados ou quando descartados, seja na sua forma inalterada, nos seus metabólitos ou produtos de transformação (DAUGHTON, 2003). Alguns componentes são excretados pela urina ou pelas fezes. Entre $80 \%$ e $95 \%$ de uma dosagem são excretados sem sofrer qualquer tipo de alteração e com isso, persistem no ambiente (UEDA et al., 2009).

De acordo com a $\mathrm{RDC} \mathrm{n}^{\circ} 222$, de 28 de março de 2018, dispõe a respeito dos requisitos de Boas Práticas de Gerenciamento dos Resíduos de Serviços de Saúde, onde os medicamentos fora da validade ou não utilizados são classificados como resíduos especiais de serviço de saúde, por apresentarem potenciais riscos à saúde púbica e ao meio ambiente. Referente ao consumo de medicamentos em domicílios, algumas pesquisas realizadas junto à população indicam que muitos usuários não sabem o que fazer com os medicamentos vencidos, assim 
como desconhecem seus impactos negativos do descarte inadequado dos mesmos (CARVALHO et al., 2009).

Os resíduos descartados são de difícil decomposição, ou seja, são caracterizados por componentes resistentes, que acabam intensificando os resíduos nocivos, afetando diversos ecossistemas (BUENO; WEBER; OLIVEIRA, 2009). Esse tipo de resíduo é classificado pela RDC 222/18, juntamente com a Resolução 358 do CONAMA (Conselho Nacional do meio Ambiente) como: resíduos da classe I, classificados como, aqueles que em função de suas propriedades físicas e químicas ou infecto contagiosas, podem apresentar riscos à saúde pública e/ou ao meio ambiente, incluindo ainda a essa classe os inflamáveis, corrosivos, reativos, tóxicos ou patogênicos. Já na classe II enquadram-se os combustíveis, biodegradáveis ou solúveis em água e por fim mais não menos importantes os de classe III, compostos por aqueles que testados a solubilização segundo a norma da ABNT NBR1004/1997 não apresenta qualquer de seus componentes solubilizados em concentrações superiores aos padrões de qualidade da água, não mudando os padrões de cor e turbidez, sabor e aspectos (SILVA, 2005).

\section{Fármaco no meio ambiente}

Os fármacos são em sua totalidade constituídos por grupos extensos e de grande diversidade de compostos orgânicos, quando utilizados em altas quantidades o que permite a recorrência não controlada de contaminação dos biossistemas (CALIMAN et al., 2009).

$\mathrm{O}$ descarte inadequado de medicações sem condições adequadas de uso, por quais quer motivos, representam alto risco para a saúde humana, animal como também para o meio ambiente. Seguindo o estudo de Oliveira (2015) são considerados os riscos:

- Interferência na saúda da vida aquática;

- Mudanças biológicas da natureza;

- Intoxicação pelo uso indevido de medicamentos vencidos ou não;

- Contaminação do solo, ar, água e alimentos;

- Intoxicação da população e contaminação, em especial aos grupos de comunidades carentes, que afetam crianças por conta de sua exposição, como é o caso dos catadores de lixo que frequentam diariamente aterros sanitários e/ou lixões, que acabam por fazerem o reuso de medicamentos descartados (ANVISA, 2010).

Os processos de eliminação dos fármacos pelo organismo humano ou animal é resultado da biotransformações, portanto, o destino final mais comum para os fármacos e seus metabolitos é o envio para ETAR (Estações de Tratamento de Águas Residuais) (PETROVIÉ et al., 2003). De modo geral, os medicamentos são descartados no lixo comum, em vasos sanitários e pias, consequentemente sendo despejados nas redes de esgoto, por sua vez contaminando o solo e água, e até mesmo aqueles medicamentos que foram consumidos acabam chegando ao meio ambiente através dos metabólitos (AKATU, 2008).

O lixo comum que é constituído por ser a principal porta de entrada para o meio ambiente para tal contaminação, devido o instante em que chega ao seu curso final (esgoto).

No caso de aterro sanitário que não conta com estruturas adequadas para destino final, com material que consegue evitar que os contaminantes passem para o solo (manta impermeabilizadora), os fármacos por consequência podem chegar até o lençol freático em concentrações altas, podendo ser até maiores do que por meio do esgoto (AWAD, 2010).

A abundância de medicamentos que entre em contato com o meio ambiente a contar do lixo doméstico é bastante considerável, já que, uma parcela variada desses poluentes é consequência da excreção dos medicamentos administrados pelo organismo ou dos resíduos de 
serviços de saúde, os medicamentos descartados no lixo comum, não passam pelos procedimentos de deterioração dos sistemas de tratamento de esgoto, portanto deixando de ser tratados como resíduos perigosos, sendo sua destinação final a mesma do lixo comum (BOUND; VOULVOULIS, 2005).

Segundo BIDONE (2001) as ampolas, medicamentos vencidos ou injetáveis representam grande parte dos problemas para meio ambiente por conta da sua carga tóxica e potencial risco de contaminação, sendo estas, uma das principais causas de intoxicação por medicamentos, além do risco de causarem acidentes por conta de perfuro cortante, gerar contaminação ou intoxicação ao simples manuseio (CALDEIRA; et al., 2010; EICKHOFF; et al., 2009; JOÃO, 2011; TESSARO; et al., 2013). Devido o consumo e administração de formas incorretas dos agentes terapêuticos á uma variação considerável de região para região. No entanto há estudo que mostram os fármacos mais utilizados e que são encontrados no meio ambiente, os mesmos são pertencentes de diferentes classes terapêuticas, com ou sem prescrição médica, destes destacam os anti-inflamatórios, antibióticos, antiepiléticos, contrastantes, esteroides sintéticos, citostáticos, antidepressivos e ainda broncodilatadores (CALISTO, 2009).

É importante ressaltar, que não se deve imputar total culpa a população pelo descarte inadequado destes medicamentos ou outros resíduos especiais provenientes de residências. Uma vez que, a falta de uma eficaz comunicação, onde mostra informações dos órgãos competentes quanto ao descarte correto e seus riscos e quando não feito de forma correta. A ausência de informações ocorre tanto por culpa da imprensa quanto nas bulas dos medicamentos e até mesmo por falta de assistência farmacêutica, por motivo de falta de paciência e tempo do paciente. Ainda que se tenha entendimento de medicamentos descartados sem critérios, que geram passivo ambiental, de difícil recuperação do solo e água que foram contaminados por estes (EICKHOFF et al., 2009).

\section{Resistência a antimicrobianos associado ao descarte doméstico de medicamentos}

A tenacidade bacteriana é uma adversidade de saúde pública ambiental e também mundial, infelizmente, delimita recurso terapêutico de infecções em motivo da manifestação de bactérias resistentes aos antibióticos, que será capaz de afetar a estabilidade dos ecossistemas em procedência tanto pelo mau uso dos antimicrobianos quanto pelo descarte das possíveis sobras (SILENE et al., 2009).

Ainda que resistência bacteriana ocorra maioritariamente em ambientes hospitalares, até antes mesmo do século XXI, Guimaraes et al., (2010) denota em estudos atuais a associação da resistência bacteriana não sendo exclusivamente do meio hospitalar mais também associado a diversos ambientes que pode atingir seres salutíferos. Segundo Nascimento et al., (2005) o advento do antibiótico foi considerado aspecto primordial aos estudos farmacológicos desenvolvidos na atualidade pelo corpo social científico. Com a solidificação das indústrias farmacêuticas, houve uma descomplexação na produção de antibióticos de origem semisintética e sintética que vinculada novos métodos de produção, tornando-se então um dos ramos mais rentáveis e consequentemente a população recebeu tratamentos contra infecções especificas por desenvolvimento de novos antimicrobianos.

Amato Neto (2000) destaca em seu estudo que a partir da descoberta da Penicilina G, em 1942, houve um gigantesco avanço da terapia medicamentosa após a inserção dos antibióticos, que contribuiu significativamente para a redução da mortandade por agentes infecciosos. 
$\mathrm{Na}$ lista dos medicamentos mais descartados estão os antimicrobianos, uma classe de medicamentos que á pouco tempo passou a ser dispensado sob retenção de receita, sendo a terceira classe de fármacos mais descartada, a liberação do mesmo no meio ambiente acaba em sua maioria resultado de seleção e indução de resistência bacteriana, por ser liberado no meio ambiente, esse tipo de descarte é muito preocupante (ROCHA, 2009).

Ao estudar a capacidade de grande potencial seletivo das bactérias e microrganismos, os órgãos responsáveis pela proteção ambiental e saúde humana perceberam que deveriam manter controle mais exigente desta classe de drogas. Tanto as bactérias como os microrganismos ao receberem ataques que não são capazes de produzir defesa para sua sobrevivenciam, acabam conseguindo tirar proveito aumentando sua resistência e sua seletividade (RIBEIRO; BINSFELD, 2013). O período essencial para o desenvolvimento de resistência microbiana mostrou ser de forma surpreendente curto para diversos antimicrobianos, o que destaca a gigantesca capacidade de adaptação dos mesmos em ambientes hostis, criados ao longo do tempo meios de modificações ainda que artificialmente pelas mãos humanas, por isso a necessidade de manter controle sobre antibióticos (PATERSON 2005) ainda que já havia o conhecimento de causa do uso irracional e prejudicial de antimicrobianos que está diretamente associado ao desenvolvimento de resistência bacteriana desde a introdução da penicilina (GOTTESMAN 2009). Descrito por Lindsey (2001) assim como outras classes de fármacos a ação de antibióticos têm diferentes efeitos sobre o meio ambiente, sendo mais utilizados na medicina humana e veterinária. Por este motivo, geralmente são detectados e em afluentes e efluentes de tratamento de esgotos municipais. Segundo Jorgensen (2002), há indícios de que o desenvolvimento de resistência antibiótica é favorecido por baixas concentrações, o que os tornam fármacos mais preocupantes devido ao aumento indiscriminado do seu consumo.

Outra preocupação dos cientistas é a utilização de antibióticos para fins não terapêuticos (sem indicação médica e sem tempo de tratamento adequado), esta ação colabora fortemente para consumir o ambiente com bactérias resistentes a antimicrobianos que contaminam o ser humano (CARVALHO et al., 2009). Na resistência de microrganismos, há dois fatores responsáveis:

- Contato de antimicrobianos com o meio ambiente onde sofrem pressão de seleção. Em resíduos de tratamento de água podem considerar como recipiente principal dos micro-organismos entéricos carreadores de genes de resistência (SCHIMIDT; CARDOSO, 2003);

- Bactérias em contato físico, no meio aquático, possibilita uma grande frequência de troca de elementos genéticos móveis (codificadores de resistência aos antimicrobianos).

Tais situações como essas são de potencial risco de proliferação da resistência a drogas como a tetraciclina (amplo espectro) (LIMA, 2006). De acordo com o conceito descrito por Lange (2002), as propriedades farmacodinâmicas e toxicodinâmicas de um composto podem facilitar a seleção dos organismos e dos testes mais relevantes para a avaliação da toxicologia. Todavia não se deverá esquecer que os alvos sobre os quais esse fármaco exerce ação podem diferir entre os mamíferos e outras espécies, sejam elas de vertebrados ou invertebrados.

Com tudo existem medidas estratégicas que podem ser empregadas para esquivar-se do desenvolvimento de resistência bacteriana como:

- Prevenção de infecções bacterianas com o uso de vacinas;

- Descarte em farmácias preparadas para recebimento desses resíduos;

- Uso racional de antibióticos (GUIMARÃES et al., 2010). 


\section{Órgãos responsáveis que amparam e fiscalizam}

Há estudos que comprovam que os medicamentos são fatores preeminentes que mais acarretam intoxicações no Brasil, ocupando a posição de primeiro lugar nos estudos estatísticos do SINITOX (Sistema Nacional de Informações Tóxico Farmacológicas) (BORTOLETTO; BOCHNER, 1999; MARGONATO et al., 2008).

Atualmente a política sanitária ambiental no Brasil, regida pelos órgãos fiscalizadores, ANVISA e o CONAMA (Conselho Nacional do Meio Ambiente) que regulamentam o gerenciamento de resíduos gerados nos Serviços de Saúde, enquadra o descarte de medicamentos como prioritário, contando com o auxilio da Resolução de Diretoria ColegiadaRDC N 44, DE 17 DE AGOSTO DE 2009, que dispõe das Boas Práticas Farmacêuticas (BPF), de critérios estabelecidos e condições básicas de controle sanitário do funcionamento, tanto da dispensação quanto da comercialização de produtos. Segundo consta nas especificações da ANVISA (2009) do capítulo VIII do artigo 93, o consentimento para que farmácias e drogarias colaborem com o programa de coleta de medicamentos em decorrência do descarte dos mesmos pela comunidade, tendo em vista preservar a saúde pública e o meio ambiente, levando em conta as convicções da biossegurança em aplicar padrões técnicos, tanto administrativas quanto normativas a fim de evitar acidentes.

Os projetos de recolhimento de medicamentos são sistemas ofertados que viabilizam programa de gerenciamento de resíduos pelo qual a grande parte da população pode realizar o descarte de seus medicamentos que por algum motivo não tiveram serventia de uso, desse modo garante o descarte seguro e gratuito, evitando que estes medicamentos sejam descartados de qualquer forma, diminuindo os danos á saúde humana e ambiental ou fiquem acumulados em residências. Este sistema é ofertando em:

- Farmácias comerciais;

- Farmácias de unidades básicas de saúde;

- Farmácias ambulatoriais de hospitais de rede pública (PIPPONZI et al., 2011).

Os programas de coleta de medicamentos têm a capacidade de diminuir o volume de medicamentos que de alguma forma permeia o meio ambiente como grandes poluentes e facilitam o uso racional de medicamentos (BUENO, 2009). O estabelecimento que não cumprir com o determinado estará sujeito à notificação de advertências e multas. Apenso a este, está a de Lei 2148/2011, que torna obrigatório a criação de pontos de coleta para recolhimento de resíduos de medicamentos nas farmácias e drogarias (BRASIL, 2011a)

Segundo Pinto (2011) o processo de coleta tem início no próprio usuário de medicamentos, que por sua fez realiza o descarte dos mesmos em locais próprios de recebimento, que são entregue aos funcionários da farmácia ou depositados em recipientes apropriados, devidamente indicados pelo estabelecimento. Estes resíduos são armazenados até que sejam coletados por empresa especializada para então serem encaminhados à destinação final mais apropriada regida por legislações que preze pela saúde pública, sendo por incineração ou em aterros de resíduos perigosos. Em estudos Awad (2010) afirma que em sua maioria as campanhas de devolução de medicamentos que existe tanto no Brasil quanto no mundo atua com a implantação da logística reversa em suas atividades.

Em relação ao método de incineração Menezes (2010) considera ser o processo mais seguro e eficiente, onde, em demasia os processos de degradação térmica composto atualmente por agregados processos, que tem grande importância em decorrência pela sua caracterização na redução de volume, sendo assim, por consequência perda de peso e de sua alta periculosidade 
gerada pelos resíduos através da combustão controlada. É primordial, que no ato da incineração, toda a ação mantenha-se conectada a um sistema desenvolvido propriamente para a depuração de gases e tratamento de líquidos de tenha com o resulta desse processo, considerando-se que os gases de um incinerador conduzem grandes proporções de substâncias em concentrações muito além dos limites das emissões do que se é legalmente permitidos, por isso há necessidade de um tratamento físico-químico adequado para remoção e neutralização de poluentes decorrentes desse processo.

Por fim a logística reversa, citada por Awad (2010) constitui-se no curso inverso de materiais, empregando os mesmos processos de um planejamento logístico convencional, que normalmente é caracterizado por armazenagem, coleta, transporte, destinação final, entretanto, essas ações ocorrem de maneira inversa, onde, o ponto de partida é pelas mãos dos clientes. Esse sistema da logística reversa é baseado no princípio da ampliação da responsabilidade do produtor da poluição pela qual o medicamento foi fabricado, pelo efeito do pós-consumo dos seus produtos (BRASILb, 2010). Cabe ao produtor se responsabilizar pela coleta e destinação adequada dos resíduos dos seus produtos pós-consumo que possuem risco ao meio ambiente (VETTORAZZI; VENAZZI 2008).

\section{A ausência do estado no descarte de medicamentos}

No ápice normativo de proteção ao meio ambiente encontra-se a Constituição da República Federativa do Brasil de 1988, que traz em seu capítulo VI, artigo 225, a proteção ao meio ambiente.

Art. 225. Todos têm direito ao meio ambiente ecologicamente equilibrado, bem de uso comum do povo e essencial à sadia qualidade de vida, impondo-se ao Poder Público e à coletividade o dever de defender e preserva-lo para as presentes e futuras gerações.

Não apenas a Constituição Federal garante o direito ao meio ambiente equilibrado, mas também imputa a responsabilidade ao Poder Público e a coletividade, de defender e preserválo para presentes e futuras gerações.

A ausência do poder público em propor e efetivar soluções para com o descarte de medicamentos residenciais se evidencia nas consequências geradas ao meio ambiente e a saúde pública, segundo o Sistema Nacional de Informações Tóxico Farmacológicas, o SINITOX, os medicamentos estão em primeiro lugar dentre os fatores que mais causam intoxicações no Brasil (BORTOLETTO; BOCHNER, 1999; MARGONATO et al., 2008).

Todavia, o poder público se contradiz com o princípio da intervenção estatal obrigatória na defesa do meio ambiente, disposto no item 17 da Declaração de Estocolmo de 1972, isso porque, o meio ambiente é um direito indisponível e bem de uso comum do povo, conforme o art. $2^{\circ}$, inc. I, da Lei ${ }^{\circ}$ 6.938/81, decorrendo daí o de dever do Estado em valer-se de todos os meios possíveis para a sua proteção (MARCHESAN; STEIGLEDER; CAPPELLI, 2010).

O descarte de medicamento engloba não apenas questões de proteção ambiental, mas também de saúde pública. Como colocado anteriormente, são as populações mais vulneráveis que tendem a sentir mais intensamente os efeitos da ausência do poder público. Não cabendo somente ao Estado, mas também aos cidadãos e indústrias farmacêuticas a defesa do meio ambiente e saúde (FALQUETO; KLIGERMAN; ASSUNPÇÃO, 2014).

No presente trabalho, a discussão do papel do Estado concentra-se sua ausência na promoção e eficiência no descarte de medicamentos, sem adentrar no instituto da responsabilidade do Estado, mas no sentido de colocar que embora haja normas como a Lei de Resíduos Sólidos, e princípios como o da precaução, poluidor pagador, prevenção, dentre 
outros advindos do direito ambiental, o correto descarte de medicamentos carece de políticas públicas que busquem promover a conscientização e informação dos cidadãos sobre o seu papel na defesa do meio ambiente (SANTOS; ROHLFS, 2012)

Importante destacar, ainda, que embora haja meios para o correto descarte de medicamento, como a logística reversa, a ausência do poder público também se revela quanto à falta de fiscalização dos procedimentos adequados, aqui expostos.

\title{
CONCLUSÃO
}

Frente aos aspectos apresentados, ficou evidente a ausência de medidas e preocupação do poder público para investimentos em fiscalizações e em campanhas que promovam a conscientização visando o descarte de medicamentos de uso residencial da população. No qual, infelizmente, as leis penosamente responsabilizam empresas geradoras de resíduos, mesmo que órgãos fiscalizadores e normatizadores como a ANVISA e o CONAMA, realizem a implementação de PGRSS, na tentativa de preencher lacunas das disposições jurídicas, ainda destaca-se a grande necessidade de atuação conjunta, não somente entre órgãos fiscalizadores e estabelecimentos geradores de resíduos, mas também, que incluía a sociedade.

Entre as principais deficiências da legislação brasileira é a não inclusão da população em geral como responsável pela destinação eficiente de resíduos, sendo medicamentos que ultrapassem o prazo de validade em suas residências, quanto a sobras medicamentosas. Estes pontos fazem com que a sociedade não tenha compreensão que a natureza por si mesma, onde, não consegue se arranjar frente a todas as degradações as quais o homem causa.

Quando houver reconhecimento e sustentação de suas responsabilidades, por meio da educação firmada desde o ensino às nossas crianças, terá então sucesso nas criações e implementações jurídicas, em virtude de realizações de denuncias ao desrespeito do meio ambiente, cobrando do estado que as regulamentações de proteção ao meio ambiente e à saúde sejam sucedidas.

\section{REFERÊNCIAS}

\author{
ALENCAR, T. O; SILVA, A. C; ROCHA M. S. C; COSTA B. R. Descarte de
} medicamentos: uma análise da prática no Programa Saúde da Família. 2014.

ANVISA. Resolução nº 222, de 29 de março de 2018. Regulamenta as Boas Práticas de Gerenciamento dos Resíduos de Serviços de Saúde e dá outras providências. Disponível em: <http://portal.anvisa.gov.br/documents/10181/3427425/RDC_222_2018_.pdf/c5d3081db331-4626-8448-c9aa426ec410>. Acesso em: 11 de maio de 2019.

ANVISA. Resolução - RDC n 44 de 17 de agosto de 2009. Instruções normativas $n^{\circ} 9$ e 10 . Boas Práticas Farmacêuticas para o controle sanitário. 2009. Disponível em: http://portal.anvisa.gov.br/documents/10181/2718376/RDC_44_2009_COMP.pdf/2180ce5f64bb-4062-a82f-4d9fa343c06e. Acessado em: 25 de maio de 2019.

ASSUMPÇÃO, D. C; KLIGERMAN; R. F; ASSUMPÇÃO. E; FALQUETO. D. C. K. Como realizar o correto descarte de resíduos de medicamentos? Revista Brasileira de Ciêntifica, v. 4, n. 2, p. 88, 2014. 
AKATU. Descarte de remédios: uma questão muito grave. Instituto Akatu, (online), 2008. Disponível em: http://www.akatu.org.br/Temas/Residuos/Posts/Mais-vida-para-o-transitodeSao-Paulo-2. Acessado em: 25 abril de 2019.

AWAD O.I; TRAVERS G.E; MOUSA S.A; Drug disposal: current recommendations and environmental concerns. Int J Pharm Res.v.4. p.1-6.2010.

BALISA, R. B. J. O Percurso Histórico da Atenção Farmacêutica no Mundo e no Brasil: Fascículo V. Conselho Regional de Farmácia do Estado de São Paulo. Organização Pan-Americana da Saúde. p.156, jun, 2010.

BRASIL. Ministério da Saúde. Conselho Nacional de Saúde. Consumo de medicamentos: um auto cuidado perigoso, 2005. Disponível em:

http://www.conselho.saude.gov.br/ultimas_noticias/2005/medicamentos.htm. Acessado em: 18 de maio de 2019.

BIDONE F.R.A. Resíduos sólidos provenientes de coletas especiais: eliminação e valorização. Rio de Janeiro: Associação Brasileira de Engenharia Sanitária e Ambiental; 2001.

BOXALL, A. B. A. Fate of Veterinary Medicines Applied to Soils. Pharmaceuticals In The Environment, p.103-119, 2004.

BORTOLETTO M.E; BOCHNER R. Impacto dos Medicamentos nas Intoxicações Humanas no Brasil. Cad Saúde Pública. v.4: p.859-69. Jan/fev 1999.

BOUND JP; VOULVOULIS N. Household. disposal of pharmaceuticals as a pathway for aquatic contamination in the United Kingdom. Environ Health Perspect. p.113.2005.

BRASILa. Câmara dos Deputados. Projeto de lei 2148 de 2011. Torna obrigatória a criação de pontos de coleta para recolhimento de resíduos de medicamentos nas farmácias e drogarias. 2011. Disponível em:

https://www.camara.leg.br/proposicoesWeb/fichadetramitacao?idProposicao=517644.

Acessado em: 16 de maio de 2019.

BRASILb. Lei ${ }^{\circ} 12.305$, de 02 de agosto de 2010b. Política Nacional de Resíduos Sólidos. Instituia Política Nacional de Resíduos Sólidos; Disponível em: < http://www.planalto.gov.br/ccivil_03/_ato2007-2010/2010/lei/112305.htm>. Acesso em: 2 de maio d 2019.

BUENO, C.S.; WEBER, D; OLIVEIRA, K.R. Farmácia Caseira e Descarte de Medicamentos no Bairro Luiz Fogliatto do Município de Ijuí - RS. Revista de Ciências Farmacêuticas Básica e Aplicada, v. 30, n. 2, p. 75-82, jan/fev,2009.

CALDEIRA, D.; PIVATO, L. S. Descarte de medicamentos domiciliares vencidos: o que a legislação preconiza e o que fazer? Artigo (Graduação em Farmácia) - Curso de Farmácia, UNINGÁ, Unidade de Ensino Superior Ingá, Maringá, 2010. 
CALIMAN, F.A; Gravrilescu, M. Pharmaceuticals, personal care producys e endocrine disrupting agents in the environment. v. 4. p. 227-303. 2009.

CALISTO, V. ESTEVES, VI. Psychiatric pharmaceuticals in the environment. Chemosphere, pp. 1257-1274, 2009.

CARNEIRO, F. Descartar medicamentos vencidos ainda é problema. Revista de Ciências Farmacêuticas Básica e Aplicada. ed.97, p.85. jan, 2011.

CARVALHO, E.V.; FERREIRA, E.; MUCINI, L.; SANTOS, C. Aspectos Legais e Toxicológicos do Descarte de Medicamentos. Revista Brasileira de Toxicologia, v. 22, n.2, p. 1-8. ago/set,2009.

CASTRO, C.G.S.O; Estudos de utilização de medicamentos: noções básicas. Rio de Janeiro: Editora FIOCRUZ, p. 92. 2000.

CELIZ, M.D; TSO, J; AGA, D.S. Pharmaceutical metabolites in the environment: analytical challenges e ecological risks. Environmental Toxicology e Chemistry, v.1, p. 2473-2484, out/nov2009.

CHRISTEN, V.; HICKMANN, S.; RECHENBERG, B.; e FENT, K. Highly ative human pharmaceuticals in aquatic systems: A concept for their identification based on their mode of action. Aquatic Toxicology, v.3. p. 167-181, ago/set,2010.

CONAMA, Conselho Nacional do Meio Ambiente. Resolução n 358, de 29 de abril de 2005: Dispõe sobre o tratamento e a disposição final dos resíduos dos serviços de saúde e dá outras providências.. Disponível em:

$<$ http://www.mma.gov.br/port/conama/legiabre.cfm?codlegi=462>. Acessado: 6 de maio de 2019.

COSTA, A. S.; COSTA, M. S. Poluentes Farmacêuticos: a poluição silenciosa. Revista de Ciências Farmacêuticas Básica e Aplicada, v.3, ed. 1, jan/fev2011.

DAUGHTON, C.G.; Cradle-to-cradle stewardship of drugs for minimizing their environmental disposition while reduction, and future directions. Environm. Health Perspectives. 111(5): p.775-785, jun/jul2003.

EICKHOFF, P.; HEINECK, I.; SEIXAS, L. J. Gerenciamento e destinação final de medicamentos: uma discussão sobre o problema. Revista Brasileira de Farmácia, v. 90, n. 1, p. 64-68, nov/dez2009.

FIRMO J.O.A.; BARRETO S.M.; COSTA, M.F. The Bambui health and aging study (BHAS): factors associated with the treatment of hypertension in older adults in the community. Cad Saude Publica. v.1 n.4 p.817-27. abr/maio2003. 
FIRMO, J.O.A.; PAREDES, A.O.; CUNHA, C.L.F.; TORRES, A.G.; BUCCINI, D.F. Análise das prescrições médicas de psicotrópicos de uma farmácia comercial no município de Bacabal, Maranhão. J Manag Prim Health Care., v. 1, n. 4, p. 10-18, 2012.

GIL, E. S.; et al. Aspectos técnicos e legais do gerenciamento de resíduos químicofarmacêuticos. Revista Brasileira de Ciências Farmacêuticas, v. 43, n. 1, p. 19-29, 2007.

GOTTESMAN, B. S. et al. Impact of quinolone restriction on resistance patterns of Escherichia coli isolated from urine by culture in a community setting. Clin. Infect. Dis., Chicago, v. 49, p. 869-875, 2009.

GUIMARAES, D. O; MOMESSO. L.P; PUPO, M. T; Antibioticos : importância terapêutica e perspectivas para a descoberta e desenvolvimento de novos agentes . Química Nova. vol.33, n.3, p.667-679. 2010.

JOAO, W. S. J. Descarte de medicamentos. Revista Brasileira de Toxicologia. Farmácia Brasileira, v. 82, p. 14-16, 2011.

JORGENSEN, J.H.; FERRARO, M.J. Antimicrobial susceptibility testing: general grown substantially over the past few years. It is important to principles and contemporary practices. Clin Infect Dis, Chicago, v. 26, p. 973-80, 1998.

JORGENSEN, J.H, TURNIDY J.D, WASHINGTON J.A. Antibacterial susceptibility tests: dilution and disk diffusion methods. Manual of Clinical Microbiology. ed.7. Washington DC: American Society for Microbiology. p.1526-1543, jan./fev 2000.

KIM, S; AGA, D.S. Potential ecological e human health impacts of antibiotics e antibiotic-resistant bacteria from wastewater treatment plants. Journal of Toxicology e Environmental Health, 10 (8), p. 559-573, 2007.

KÜMMERER, $K$. The presence of pharmaceuticals in the environment due to human use - present knowledge and future challenges. J Environ Manage. p,54-66, 2009.

LANGE, M.R.J. Adverse drug reactions and interactions. Pharmacotherapy: a pathophysiologic approach. Norwalk: Appleton e Lange, p.101-116. 2000.

LIMA, R. M. S.; FIGUEIREDO, H. C. P.; PICOLLI, F. C. F. R. H.; FILHO, J. S. S. B.; LOGATO, P. V. R. Resistência a Antimicrobianos de Bactérias Oriundas de Ambiente de Criação e Filés de Tilápias do Nilo (Oreochromis niloticus). Ciência e Agrotecnologia, Lavras, v. 30, n 01. p. 126-132. jan./fev, 2006.

LINDSEY, et al., Endocrine disruption: Whay is it so complicated? Water Qual. Res. J. Can., v.36, p. 175-190. 2001.

MARCHESAN, A. M. M; STEIGLEDER A. M; CAPPELLI S. Direito Ambiental. Série Concursos. Porto Alegre, Ed. 6 Verbo Jurídico, 2010. p. 65 e 213-220. 
MARGONATO, F; THOMSON Z; PAOLIELLO M.M.B. Determinantes nas intoxicações medicamentosas agudas na zona urbana de um município do Sul do Brasil. Cad Saúde Pública. V.4. p.47. jan/fev,2008.

MENDES, Z; CRISÓSTOMO. S, MARQUES. F.B, MARTINS. A.P, RODRIGUES. V, RIBEIRO.C.F . Desperdício de medicamentos no ambulatório em Portugal. RPMGF Revista Portuguesa de Medicina Geral e Familiar. vol;26. n.1. p.12-20. mar/abr, 2010.

MENEZES, R.A.A, GERLACH J.L, MENEZES M.A. VII Seminário Nacional de Resíduos Sólidos e Limpeza Pública. Curitiba. Revista Brasileira de Farmácia. v.3. p.122125. 2010.

NASCIMENTO, G.G, LOCATELLI J, FREITAS P.C, SILVA G.L. Atividade antibacteriana de extratos vegetais e fitoquímicos em bactérias resistentes a antibióticos. Braz J Microbiol. v31. p.56. 2000.

NETO, A; et al. Antibióticos na prática médica, resistência bacteriana a antibióticos. São Paulo. 5. ed. v. 4, p.51-64.2000.

OLIVEIRA, A. Descarte do lixo hospitalar. Revista Comissão Técnica Nacional de Biossegurança (CTNBio). p.22. 2015.

ORGANIZACIÓN MUNDIAL DE LA SALUD. Uso racional de los medicamentos. Informe de la Conferencia de Expertos. Nairobi. p.304, 29 de nov 1985.

PATERSON, D. L.; BONOMO, R. A. Extended-spectrum b-lactamases: a clinical update. Clin. Microbiol. Rev., Washington, v. 18, p. 657-686, 2005.

PETROVIÉ. M; GONZALEZ. S; BARCELÓ. D. Analysis and remova! of emerging contarninants in wastewater and drinking water. Ii-ends in Analytical Cbemistiy 22. p.685-696. 2003.

PIPPONZI, C. Programa Descarte Consciente. Revista Brasileira de Farmácia, v.4. p.56. set/nov, 2011

PINTO, V.B. Programa de devolução segura de medicamentos e o gerenciamento de resíduos. Revista Brasileira de Farmácia. v.2. p.152-155. Jan/fev,2011.

PONEZI, N.A; DUARTE M.C.T., CLAUDINO M.C. Fármacos em matrizes ambientais. Centro Pluridisciplinar de Pesquisas Químicas, Biológicas e Agrícolas, Universidade Estadual de Campinas. ago.set, 2008.

QUELUZ, T.H.A.T.; LEITE, S.N. Uso racional de medicamentos: conceito e alguns elementos para discussão, Univali. p. 25-40, Jun, 2008.

REIS, M. O.;OLIVEIRA, L. S.; ROCHA, S. D. Adsorventes de Resíduos. Congresso Brasileiro de Engenharia Química em Iniciação Científica, VI. São Paulo.2005. 
RIBEIRO, M. A.; BINSFELD, P. C. Descarte de Medicamentos Vencidos ou Não

Utilizados: Riscos e Avanços Recentes. Ciência, saúde e esporte. p. 1076-1092, jan, 2013.

ROCHA, B.S.; HEINECK I, AMADOR, T.A, SEIXAS L.M.J, GALINA S.M, SALVADORETI. C. Caracterização dos medicamentos descartados por usuários da farmácia popular do Brasil. Farmácia escola da Universidade Federal do Rio Grande do Sul (UFRGS). P.19-25,set2009.

RODRIGUES, C.R.B. Aspectos legais e ambientais do descarte de resíduos de medicamentos. Dissertação. Mestrado em Engenharia de Produção). Universidade Tecnológica Federal do Paraná, Ponta Grossa. Jan/fev2009.

SANTOS, Amanda Leão dos; ROHLFS, Daniela Buosi. A responsabilidade pelo descarte de medicamentos a luz da Política Nacional de Resíduos Sólidos. 4. ed. Minas Gerais: D, 2012.

SCHENKEL, E. P.; MENGUE, S. S.; PETROVICK, P. R. Cuidados com os. medicamentos. ed. Porto Alegre: Editora UFRGS, Ciência da educação. (Bauru) v. no.1. 2004.

SCHIMIDT, V.; CARDOSO, M.R.I. Sobrevivência e Perfil de Resistência a Antimicrobianos de Salmonella Sp. Isoladas em um Sistema de Tratamento de Desejos de Suínos. Ciência Rural, Santa Maria, v. 33, n. 5, p. 881-888. set-out, 2003.

SILENE A. S. M; TROVÓ. G.A; BAUTITZ, I.R; PUPO. F.N. Degradação de fármacos residuais por processos oxidativos avançados. Química. Nova vol.32 no.1 São Paulo 2009.

SILVA E. Problematizando o descarte de medicamentos vencidos: para onde destinar? Monografia (Curso Técnico em Vigilância Sanitária e Saúde Ambiental), Escola Politécnica de Saúde Joaquim Venâncio. Rio de Janeiro: FIOCRUZ, p.50.2005.

TESSARO, P. B.; ZANCANARO, V. Recolhimento e descarte dos medicamentos das farmácias caseiras no município de Caçador - SC. Saúde Meio Ambiente, v. 2, n. 1, p. 118-28, 2013.

UEDA, J.; TAVERNARO, R.; MAROSTEGA, V.; PAVAN, W. Impacto Ambiental do descarte de fármacos e estudo da conscientização da população a respeito do problema. Revista Ciências do Ambiente. v. 5, n. 1. 2009.

VETTORAZZI, K. M.; VENAZZI, K. F. Responsabilidade socioambiental dos produtores de medicamentos e farmácias sobre os resíduos sólidos de saúde: a logística reversa como possibilidade de coleta e correta destinação. Revista Ciência e tecnologia FATECCentro Universitário, Cascavel-PR, 2008.

WHO; WORLD HEALTH ORGANIZATION. The state of world health: life expectancy, health expectancy, 1997. 
ZIYLAN, A; INCE, N.H. The occurrence e fate of anti-inflammatory e analgesic pharmaceuticals in sewage e fresh water, treatability by conventional e nonconventional processes. Journal of Hazardous Materials, v.2, p.24-36. 2011.

Publicado em 29/10/2020 